\title{
Metabolic Engineering of Bacillus subtilis for 2.3-BDO production by introducing an exogenous NADPH/NADP+ regeneration system
}

\author{
Huiling Liu \\ Jiangnan University \\ Shuangying Liu \\ Jiangnan University \\ Fengyu Xie \\ Jiangnan University \\ Xian Zhang \\ Jiujiang University \\ Meijuan Xu \\ Jiangnan University \\ Minglong Shao \\ Jiangnan University \\ Haitian Fang \\ Ningxia University \\ Huiling Zhang \\ Ningxia University \\ Taowei Yang \\ Jiangnan University \\ Zhiming Rao ( $\nabla$ raozhm@jiangnan.edu.cn ) \\ Jiangnan university https://orcid.org/0000-0003-2495-0660
}

\section{Research}

Keywords: 2,3-butanediol, cofactors regeneration, transcriptional regulator, Bacillus subtilis

Posted Date: December 10th, 2019

DOI: https://doi.org/10.21203/rs.2.18380/v1

License: (a) (1) This work is licensed under a Creative Commons Attribution 4.0 International License. Read Full License 


\section{Abstract}

Background: Generally, glucose is transformed into pyruvate from glycolysis before the target products acetoin and 2,3butanediol (2,3-BDO) are formed. Pentose Phosphate Pathway (PPP) is an inefficient synthetic pathway for pyruvate production from glucose in Bacillus subtilis. Previously, it was found that engineered PPP in B. subtilis unbalanced NADH and NADPH regeneration systems and affected acetoin and 2,3 -BDO production.

Results: In this study, metabolic engineering strategies were proposed to redistribute carbon flux to 2,3-BDO via reconstructing intracellular cofactors regeneration systems. Firstly, extra copies of glucose dehydrogenase (GDH)and an exogenous NADPH-dependent 2,3-BDO dehydrogenase (TDH) were introduced into the GRAS strain $\mathrm{B}$. subtilis 168 to introduce an exogenous NADPH/NADP + regeneration system and broaden 2,3-BDO production pathway. It was found that overexpressing the NADPH/NADP + regeneration system effectively improved 2,3-BDO production and inhibited NADHdependent by-products accumulation. Subsequently, the disruption of lactate dehydrogenase (encoded by Idh ) by insertion of the transcriptional regulator ALsR, essential for the expression of alsSD (encoding two key enzymes for the conversion of pyruvate to acetoin) in B. subtilis, resulted in the recombinant strain in which alsSD was overexpressed and the pathway to lactate was blocked simultaneously. On fermentation by the result engineered strain, the highest 2,3-BDO concentration increased by $18.43 \%$, while the titers of main byproducts acetoin and lactate decreased by $22.03 \%$ and $64 \%$, respectively.

Conclusion: In this study, it shows that engineering PPP and reconstructing intracellular cofactors regeneration system could be an alternative strategy in the metabolic engineering of 2,3-BDO production in $\mathrm{B}$. subtilis .

\section{Background}

2,3-butanediol $₫ 2$.3-BDO囚is an important platform compound and it has important applications in industry [1-3]. As a potential environmentally friendly fuel, the heating value of 2.3-BDO is $27.2 \mathrm{~kJ} / \mathrm{g}$ [4] comparing with ethanol $29.055 \mathrm{~kJ} / \mathrm{g}$ and methanol $22.081 \mathrm{~kJ} / \mathrm{g}$ [5], it can mixed with gasoline in any proportion. Due to the shortage of fossil fuels, the production of 2,3- BDO is catching more attentions [1].

The microorganisms, which can produce 2,3-BD0, are Serratia marcescens [6], Klebsiella [7], Bacillus polymyxa [8], $B$. amyloliquefaciens [9], etc. Compared with other known 2,3-BDO producing strains, $B$. subtilis is also superior for its GRAS status that meets safety regulations for industrial-scale fermentation [10]. In the metabolic pathway of 2, 3-BDO, glucose is transformed into pyruvate from glycolysis before 2,3-BDO is formed and then, pyruvate is converted into acetoin under the acetolactate synthase(ALS) and acetolactate decarboxylase(ALDC) $\varangle$ Figure 1区[11, 12]. 2,3-BDO is synthesized under the 2,3BDO dehydrogenase with the acetoin as substrate [13].

In recent years, production of 2, 3-BDO by microorganisms has been greatly developed by regulating NADH regeneration system. Yang et al. improved 2,3-BDO production by $22.7 \%$ in B.amyloliquefaciens via rebuilding NADH/NAD ${ }^{+}$regeneration system by co-overexpression of Glyceraldehyde-3-Phosphate Dehydrogenase /2,3-butanediol Dehydrogenase [14], and increased 2,3-BDO titer by $25.5 \%$ in $B$. subtilis via introducing an extra NADH regeneration system and disrupted NADH oxidase [15]. Fu et al. successfully enhanced the 2,3-BDO titer by $13.6 \%$ with the introduction of transhydrogenase to improve the NADH yield from NADPH in B. subtilis [16]. Dai et al. simultaneously increased 2,3-BDO titer by the higher NADH/NAD ${ }^{+}$ratio in Paenibacillus polymyxa with additional vitamin $\mathrm{C}$ in the fermentation medium [17]. These regulatory strategies were all based on regulating NADH levels. In this study, we payed more attentions to regulate a different cofactor NADPH levels and tried to improve 2, 3-BDO titer by reconstructing a NADPH/NADP ${ }^{+}$regeneration system.

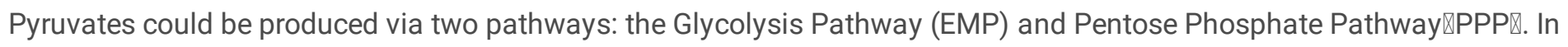
the EMP, one glucose produces two pyruvates accompanying with two molecules of NADH [1]. While, through the PPP, pyruvate is produced accompanying with NADPH production [18]. In our previous study, it was found that acetoin could be enhanced by engineering the PPP pathway and disturbing the coenzyme balance of NADH/NADPH[19]. In this study, we tried 
to introduce extra copies of glucose dehydrogenase(GDH)[20] and an exogenous NADPH-dependent 2,3-BDO dehydrogenase(TDH)[21] into the GRAS strain $B$. subtilis 168 to introduce an exogenous NADPH/NADP ${ }^{+}$regeneration system and observed their effects on 2,3-BDO fermentation.

\section{Result}

\section{Engineering of pentose phosphate pathway and its effects on glucose fermentation to 2,3-BDO in B. subtilis}

Pyruvate is the precursor of acetoin [11, 12]and a key intermediate product in glucose metabolism [12]. There are main two pathways for production pyruvate in microorganisms: EMP and PPP. Pyruvate can be produced via EMP and PPP in microorganisms. GDH (encoded by $g d h$ ), one of the key enzymes in the gluconate production, catalyzes the conversion of glucose to gluconate accompanying with $\mathrm{NADH}$ and NADPH. Gluconate is converted into pyruvate through the pentose

phosphate pathway $[19,22]$. In this work, GDH under different strength promoters $P_{b d h A}$ [23], $P_{\text {pac }}, P_{\text {Spac }}$ [24] and $P_{\text {Hpall }}$ were separately overexpressed into Bacillus subtilis, and the resultant strains were BM1, BM2, BM3, BM4, respectively.

The fermentation results showed that overexpression of GDH in engineered strains repressed the cell growth and 2,3-BDO production and extended the fermentation period in medium containing $100 \mathrm{~g} / \mathrm{L}$ glucose $\ T a b l e ~ 3 \otimes$. The yield of byproduct acetoin was increased by $17.6-37.8 \%$, but 2,3-BDO, lactate and ethanol decreased by $15.1-22.3 \%, 15.2-23.3 \%, 32.3-37.6 \%$ respectively. It might indicate that overexpression of GDH disturbed the NADH and NADPH regeneration systems and repressed 2,3-BDO fermentation.

\section{Introducing an exogenous NADPH-dependent 2, 3-butanediol dehydrogenase to construct the NADPH/NADP ${ }^{+}$regeneration system in engineered $B$. subtilis strains}

Overexpression of GDH increased the level of NADPH and decreased NADH levels which repressed the conversion of acetoin to 2,3-BDO. To enhance the carbon flux to 2,3-BDO, we tried to introduce an exogenous NADPH-dependent 2,3-BDO dehydrogenase[21] (coding gene $t d h$ in Clostridium autoethanogenum DSM 10061囚into engineered B.subtilis to construct an extra NADPH/NADP ${ }^{+}$regeneration system with help of $\mathrm{GDH}$, and observed their effects on 2,3-BDO fermentation.

In eukaryotes, poly $\triangle A \otimes$ tails are stretch adenine bases in the 3 ' end of RNA, and it was found that when the poly $(A)$ tails become short enough, the mRNA could be degraded. It was also reported that the different of poly(A) tails had a great effect on the stability of mRNA of the enzyme, which plays a key role in its overproduction process [25-27].

In this study, to improve the efficiency of carbon flow from acetoin to 2,3-BDO, poly (A) tails (AAATTT, TTTAAATTT, AAATTTAAATTT, TTTTTTAAATTT and TTTTTT) were separately added to the 3 ' end of the tdh to improve its transcription abundance and TDH production in B. subtilis, and the resultant strains named BM6, BM7, BM8, BM9 and BM10, respectively. The results were showed in Figure 2. The transcription abundance of tdh in strains BM6, BM7, BM8 and BM9 were all decreased, compared with strains BM5 without any poly $(A / T)$ tails, and the lower transcription abundance resulted in lower TDH activities in strains BM6, BM7, BM8 and BM9. However, compared with strains BM5, the transcription abundance of TDH in strain BM10 increased by $85 \%$, which resulted in the TDH activity reached to $180.35 \mathrm{mu} / \mathrm{mg}$ and increased by 32.6 $\%$.

Subsequently, the TDHR5 and $g d h$ with different promoters were co-overexpressed in $B$. subtilis 168 resulting in recombinant strains BM11, BM12, BM13 and BM14 (Tale 3). It was observed that fermentation times were shortened significantly, the NADPH levels were decreased, and the yields of 2.3-BDO were increased but the acetoin titer was decreased when compared with GDH solely overexpressed strains BM2, BM3, BM4 and BM5 (Tale 3). The strain BM12 (GDH under promoter $\mathrm{P}_{\text {pac }}$ ) 
showed the highest titer of 2,3-BDO which was increased by $39.64 \%$ while the acetoin titer was decreased by $36.82 \%$, which suggested that excessive NADPH was used for the synthesis of 2,3-bdo, and more acetoin was catalyzed to 2,3-bdo.

When compared with the parental strain B.subtilis 168, it could be found that introduction of an efficient exogenous $\mathrm{NADPH} / \mathrm{NADP}^{+}$regeneration system (co-overexpressing GDH and TDH) in strain BM12 increased 2,3-BDO titer by $14.01 \%$ and total amount of acetoin and 2,3-BDO by $3.05 \%$ while decreased the titers of NADH-dependent by-products lactate and ethanol by $12.82 \%$ and $23.65 \%$, respectively. It indicated that we successfully redistributed the carbon flux to $2,3-\mathrm{BDO}$ pathway by regulating cofactors regeneration systems in $B$. subtilis.

\section{Redistributing the carbon flux to 2,3-BDO by overexpressing the transcriptional regulator ALsR and blocking the pathway to lactate}

ALsR is a LysR-type transcriptional regulator, which could regulate the alsSD operon, encoding the key enzyme (ALS and ALDC), catalyzing pyruvate to acetoin $[28,29]$. To redistribute more carbon flux to 2,3-BDO pathway, ALsR under promoter $\mathrm{P}_{\text {sffA }}[30]$ was overexpressed by integrated into the chromosome of BM12 at /dh(encoding lactate dehydrogenase, LdhA) locus, resulting in strain BM15. The multiple copies of alsr improved the activities of als (from $1.0 \mathrm{U} / \mathrm{mg}$ to $1.75 \mathrm{U} / \mathrm{mg}$ ) and aldc (from $0.51 \mathrm{U} / \mathrm{mg}$ to $0.75 \mathrm{U} / \mathrm{mg}$ ) by $75 \%$ and $47.05 \%$ and decreased the activity of LdhA by $89 \%$ when compared with strain BM12. Shown in Table 3.

As shown in Figure 3A, the cell density has no obvious change among BM0, BM12 and BM15. However, the introduction of extra copies of alsR and disrupt of $I d h$ in strain BM15 resulted in faster glucose consume rate, increased 2,3-BDO by $2.5 \%$ and decreased acetoin and lactate titer by $10.34 \%$ and $59.03 \%$ compared with strain BM12.

Furthermore, when compared with parental strain B.subtilis 168, through all above metabolic engineering strategies in strain BM15, we shortened the fermentation time from 72 hours to 70 hours, increased 2, 3-BDO titer and total titer of acetoin and 2,3-BDO by $18.35 \%$ and, while decreased the titers of acetoin and NADH-dependent by-products lactate by $30.64 \%$ and $64.28 \%$ respectively(Figure3).

\section{Discussion}

As fossil fuels become increasingly scarce, bio-production of 2,3-BDO is attracting increasing attention [1]. Generally, sugars are converted into pyruvate mainly from glycolysis before the target product 2,3-BD is formed [11]. As known that pyruvates could be also produced via PPP. However, it was found that PPP is an inefficient synthetic pathway for pyruvate production from glucose in $B$. subtilis [19]. GDH (encoding by $g d h$ ) is one of the key enzymes catalyzes the conversion of glucose to gluconate which enter PPP [19]. Thus, we tried to overexpress GDH in B. subtilis to enhance the metabolic efficiency of PPP and broaden the pathways from glucose to pyruvate. It was found that overproduction of GDH in $B$. subtilis increased NADPH levels and acetoin accumulation but decreased NADH levels and 2,3 -BDO production, and extended the duration. The disturbed levels of cofactors should be responsible for inhibited carbon utilization rate. Lower levels of NADH decreased NADH-dependent products 2,3-BDO, lactate and ethanol production. Insufficiency NADH availability inhibited transformation of acetoin to 2, 3-BDO, so acetoin accumulated more.

In 2,3-BDO biosynthesis pathway, it contains a series of redox reactions which participate in regulating the NADH/NAD ratio in bacteria [14]. Overproduction of GDH in B. subtilis disturbed NADH and NADPH levels and repressed 2,3-BDO fermentation. Thus, we need introduce an exogenous NADPH/NADP ${ }^{+}$regeneration system to rebalance cofactors regeneration system in $B$. subtilis and improve 2,3-BDO fermentation. NADPH-dependent 2.3-BDO dehydrogenase could be found in anaerobic microorganisms such as Clostridium beijerinckii [31] and Clostridium. autoethanogenum [21].

Some cofactors metabolic engineering strategies have been employed to improve 2, 3-BDO production and repress byproducts production by manipulating NADH levels. To improve the NADH yield from NADPH in $B$. subtilis, Fu et al. introduced 
a transhydrogenase and successfully enhanced the 2,3-BDO titer by $13.6 \%$ [16]. In previous study, we manipulated NADH levels in $B$. subtilis by introducing an extra NADH regeneration system (Formate dehydrogenase and formate) while simultaneously disrupting the NADH oxidase and / $d h$ genes, which increased the 2,3-BDO titer by $25.5 \%$, with a concomitant decrease acetoin (by 76.4\%) and lactate (by 80.5\%) accumulation [15]. Inspired by these results, we tried to set up a $\mathrm{NADPH} / \mathrm{NADP}^{+}$regeneration cycle to redistribute the carbon flux to 2,3-BDO with NADPH as cofactor. As it was expected, when a NADPH-dependent 2.3-BDO dehydrogenase was successfully co-overexpressed with GDH in $B$. subtilis, it significantly increased the 2,3-BDO production and sharply decreased acetoin and NADH-dependent by-products lactate and ethanol formation, and shortened the fermentation duration. It indicated that we successfully redistributed the carbon flux to 2,3-BDO pathway and improve the consumption rate of glucose by reconstructing the NADPH/NADP ${ }^{+}$regeneration systems in $B$. subtilis.

In bacterial metabolism, ethanol, acetoin, lactate, and other end-products are also produced during 2,3-BD fermentation [32]. Therefore, 2,3-BD biosynthesis must compete with multiple pathways for the pyruvate and NADH resources, which remains prohibitively low for commercial production of 2,3-BDO. To improve the yield of 2,3-BDO, overproduction of key enzymes involved in the 2,3-BDO pathway and blocking the unwanted by-products pathways are all alternative strategies. ALsR acts as the regulatory gene of alsSD operon encoding ALS and ALDC, which is responsible for acetoin biosynthesis [28, 29]. Some researchers had tried to overexpressing ALS and ALDC to enhance the acetoin production. However, the higher activities of ALS and ALDC suppressed the cell growth, the acetoin yield was not significantly increased [23, 33]. Zhang et al. attempted to control ALS and ALDC by moderately enhancing the expression of AlsR, and successfully improved the yield of acetoin by $62.9 \%$ in B. subtilis [23]. The deletion of adhE (encoding alcohol dehydrogenase) and Idh gene (encoding lactate dehydrogenase) could block the carbon flux toward ethanol and lactate biosynthesis increase the available NADH for 2,3-BD formation [34-36]. In this study, to redistribute the carbon flux to 2,3-BDO ,we tried to regulate the expression level of ALsR using the promoter $P_{\text {srfA }}$, which is self-induced and transcribes at the middle and late stage of fermentation [30]. The fused

gene fragment $\mathrm{P}_{\text {srfA }}$-ALsR was inserted into the location of $/ d h$ in the $B$. subtilis genome, which resulted in the recombinant strain in which ALsR was overproduced and Idh was disrupted simultaneously. It was found that the lacking of $/ d h$ and extra copies of ALsR in B. subtilis resulted in more carbon to flow into the 2, 3-BDO synthesis pathway, and increased the 2, 3-BDO titer by $18.35 \%$ and decreased the yields of by-products AC, lactate and ethanol by $22.03 \%, 64.28 \%$ and $25.80 \%$ respectively. The fermentation duration was shortened to $70 \mathrm{~h}$.

\section{Conclusion}

In this study, we proposed an alternative strategy to regulate the carbon flux toward 2,3-BDO by introducing an exogenous $\mathrm{NADPH} / \mathrm{NADP}^{+}$regeneration system, overexpressing ALsR under the promoter $\mathrm{P}_{\text {srfa }}$ and disrupting /dh gene simultaneously. The production of 2,3-BDO was increased, and the by-products production of acetoin, and lactate and ethanol were decreased significantly, which indicated that engineering of NADPH coenzyme cycles could improve 2,3-BDO production and suppress the by-products accumulation.

\section{Materials And Methods}

\section{Bacterial strains, primers, and plasmids}

All bacterial strains used are described in Table 1. All primers and plasmids used in this study are described in Table 2

\section{Culture conditions}

Strains were cultured in Luria-Bertani medium at $37^{\circ} \mathrm{C}$ on a rotary shaker at $180 \mathrm{rpm}$, if necessary, add $50 \mathrm{mg} / \mathrm{L}$ of Kana Magnesium, $100 \mathrm{mg} / \mathrm{L}$ ampicillin or $3 \%$ bleomycin into the medium. 
For 2,3-BDO fermentation, the fermentation medium included $100 \mathrm{~g} / \mathrm{L}$ glucose, $5 \mathrm{~g} / \mathrm{L}$ yeast extract $20 \mathrm{~g} / \mathrm{L}$ corn syru and 2 $\mathrm{g} / \mathrm{L}$ urea, $\mathrm{pH}$ 6.8. The fermentation medium was sterilized at $121^{\circ} \mathrm{C}$ for $20 \mathrm{~min}$. The seed was cultured in the $\mathrm{LB}$ at $37^{\circ} \mathrm{C}$ on a rotary shaker at $180 \mathrm{rpm}$ for $12 \mathrm{~h}, 3 \mathrm{~mL}$ seed was inoculated into $50 \mathrm{~mL}$ fermentation medium at $180 \mathrm{rpm}$ and $37^{\circ} \mathrm{C}$.

\section{The construction plasmids and Strains}

The promoter $\mathrm{P}_{\mathrm{bdhA}}$ and gene $g d h$ was amplified from the $B$. subtilis 168 genome by the primers $\mathrm{P} 1$ and $\mathrm{P} 2, \mathrm{P} 9$ and $\mathrm{P} 10$ respectively, the promoters Ppac and Pspac were synthesized in Genewize company. It was obtained by PCR by primers P3 and P4, P5 and P6. Promoters $\mathrm{P}_{\text {bdhA }}, \mathrm{P}_{\text {pac }}, \mathrm{P}_{\mathrm{Spac}}, \mathrm{P}_{\mathrm{Hpall}}$ and gdh genes connected together by overlap extension PCR(SOE PCR) [37], then insert to the site of ECoR/ in pMA5. For the construction of pMA5-P Hpall $^{-T D H R X ~(X ~ w a s ~ f r o m ~ 1 t o ~ 5), ~ t h e ~ g e n e ~}$ tbdh was synthesized in Genewize company, TDH, TDHR1, TDHR2, TDHR3, TDHR4, TDHR5, design with were obtained by PCR with primers p11 and p12, p13, p14, p15, p16, p17 respectively, and then ligated into the vector pMA5 at Ndel and BamHI restriction sites. For the pMA5- $\mathrm{P}_{\text {Hpall }}$ TDHR5-Ppac- $g d h$ construction, firstly construct pMA5- $\mathrm{P}_{\text {Hpall }}$ TDHR5, then inserted $g d h$ under different promoters insert to the site of EcoRI of pMA5. All ligation between genes and vector were used Clon Express II One Step Cloning Kit (Vazyme Biotech in NanJing, China).

Gene alsR and the promoter $\mathrm{P}_{\text {srfA }}$ were amplified by PCR by primers P26 and P27, P24 and P25, respectively. The gene zeo was amplified from p7z6 by primers P18 and P19. IdhA-F (1000 bp upstream IdhA gene in genome) and IdhA-R (1000 bp downstream IdhA gene in genome) were obtained by primers P20 and P21, P22 and P23, respectively. Then, IdhA-R, IdhA$\mathrm{F}, z e o, \mathrm{P}_{\text {srfA }}$ and alsR were connected together through SOE-PCR.

The method of transform plasmid or DNA fragments into Bacillus subtilis 168 reference the method described by Vojcic et al. [38]

\section{Enzyme assays}

To determine acetoin reductase (ACR) activity, bacteria was cultured overnight, the cells were collected by centrifugation for 5 min at $8000 \mathrm{rpm}$, and washed with $0.1 \mathrm{M} \mathrm{pH} 7.0$ phosphate buffer for three times. ACR activity was assayed spectrophotometrically by monitoring the change in absorbance at $340 \mathrm{~nm}$ corresponding to the reduction of NADPH at $37^{\circ} \mathrm{C}$ in a total volume of $1 \mathrm{~mL} 0.1 \mathrm{M}$ phosphate buffer containing $0.2 \mathrm{mM}$ NADPH and $50 \mathrm{mM}$ acetoin. The enzyme activity unit was defined that the amount of enzyme required to consume $1 \mu \mathrm{mol} / \mathrm{L}$ NADPH per minute. Total protein concentrations were determined according to the Bradford method.

To determine the activity of $\mathrm{LdhA}$, the total volume of $1 \mathrm{~mL} 0.1 \mathrm{M}$ phosphate buffer》pH 7.2区containing $0.2 \mathrm{mM}$ NADH and 10 $\mathrm{mM}$ sodium pyruvate was assayed spectrophotometrically by monitoring the change in absorbance at $340 \mathrm{~nm}$ corresponding to the reduction of $\mathrm{NADH}$ at $37^{\circ} \mathrm{C}$, the enzyme activity unit was defined that the amount of enzyme required to consume $1 \mu \mathrm{mol} / \mathrm{L}$ NADH per minute.

The enzyme activities of ALS[39]and ALDC[40] asssys were performed according to published procedures.

\section{Quantitative real-time PCR (qRT-PCR)}

To determine the transcription abundance of $t d h$, cells cultured 8-10 $\mathrm{h}$ were harvested at room temperature and immediately frozen in liquid nitrogen. the total RNA of bacteria was extracted using Bacteria RNA Extraction Kit (Vazyme Biotech in NanJing, China), and then reverse-transcribed into cdna, which was used as the template for rt-pcr. Expression levels of different $t b d h$ genes were measured with primers p28 and P29. The 16S rRNA gene was used as the internal standard with primers $\mathrm{p} 30$ and P31. 


\section{Detection of metabolites}

The cell mass density was determined from the OD at $600 \mathrm{~nm}$ in an ultraviolet (UV)-visible spectrophotometer (UNICO UV2000 spectrophotometer, Shanghai, China). Glucose, 2,3-BD and acetoin were analyzed using high performance liquid chromatograph (HPLC) system (Agilent Corp., USA) with RID detector. The column and mobile phases were Hi-Plex Ca (4.6 x $250 \mathrm{~mm}$ ) (Agilent, USA) and ultrapure water at $0.4 \mathrm{ml} / \mathrm{min}$, respectively. Lactate and ethanol were detected by HPLC used column HPX-87H (BioRad) with a mobile phase of $2.5 \mathrm{mM} \mathrm{H}_{2} \mathrm{SO}_{4}$ at $55^{\circ} \mathrm{C}$. The NAD/NADH Quantitation Kit for NADH detection, the NADPH Quantitation Kit for sigam for NADPH detection.

\section{Declarations}

\section{Ethics approval and consent to participate}

Not applicable

\section{Consent for publication}

Not applicable

\section{Availability of data and materials}

The datasets used and/or analysed during the current study are available from the corresponding author on reasonable request.

\section{Competing interests}

The authors declare that they have no competing interests.

\section{Funding}

This work was supported by the National Natural Science Foundation of China (21778024), the National Key Research and Development Program of China (2018YFA0900304), National First-Class Discipline Program of Light Industry Technology and Engineering (LITE2018-06), the Program of Introducing Talents of Discipline to Universities (111-2-06), key research and development program of Ningxia hui autonomous region (2017BY069), the science and technology innovation team foundation of Ningxia hui autonomous region (KJT2017001), Top-notch Academic Programs Project of Jiangsu Higher Education Institutions and the Priority Academic Program Development of Jiangsu Higher Education Institution.

\section{Authors' contributions}

LL conceived of the study, performed the data analysis, and coordinated the manuscript draft and revision. SY, TY, XF executed the experimental work and data analysis. TY, ZX, ZR, MX, sl helped to revise and proofread, coordinated the manuscript.

\section{Acknowledgements}

Not applicable

\section{Abbreviations}

2,3-BD0:2,3-butanediol; PPP:Pentose Phosphate Pathway; EMP:Glycolysis Pathway; GDH:glucose dehydrogenase; TDH:NADPH-dependent 2.3-BDO dehydrogenase; ALS:cetolactate synthase; ALDC:acetolactate decarboxylase; GRAS:generally regarded as safe; LdhA:lactate dehydrogenase. 


\section{References}

1. Celinska E, Grajek W. Biotechnological production of 2,3-butanediol--current state and prospects. Biotechnol Adv. 2009;27(6):715-725.

2. Ji XJ, Huang H, Ouyang PK. Microbial 2,3-butanediol production: a state-of-the-art review. Biotechnol Adv. 2011;29(3):351-364.

3. Yang T, Rao Z, Zhang X, Xu M, Xu Z, Yang ST. Metabolic engineering strategies for acetoin and 2,3-butanediol production: advances and prospects. Crit Rev Biotechnol. 2017;37(8):990-1005.

4. Li L, Li K, Wang Y, Chen C, Xu Y, Zhang L, et al. Metabolic engineering of Enterobacter cloacae for high-yield production of enantiopure (2R,3R)-2,3-butanediol from lignocellulose-derived sugars. Metab Eng. 2015;28:19-27.

5. Flickinger MC, Jansen NB, Forrest EHJB. Mobile self-contained off-gas analysis units for fermentation pilot plants. Biotechnol Bioeng.1980;22(6):1273-1276.

6. Zhang L, Sun J, Hao Y, Zhu J, Chu J, Wei D, et al. Microbial production of 2,3-butanediol by a surfactant (serrawettin)deficient mutant of Serratia marcescens H30. J Ind Microbiol Biotechnol. 2010;37(8):857-862.

7. Metsoviti M, Paraskevaidi K, Koutinas A, Zeng A-P, Papanikolaou S. Production of 1,3-propanediol, 2,3-butanediol and ethanol by a newly isolated Klebsiella oxytoca strain growing on biodiesel-derived glycerol based media. Process Biochem. 2012;47(12):1872-1882.

8. RB H. Fermentation of Xylan, Corn Fiber, or Sugars to Acetoin and Butanediol by Bacillus polymyxa Strains. Curr Microbiol 1996;32:291-296.

9. Yang T, Rao Z, Zhang X, Lin Q, Xia H, Xu Z, et al. Production of 2,3-butanediol from glucose by GRAS microorganism Bacillus amyloliquefaciens. J Basic Microbiol. 2011;51(6):650-658.

10. Deboer AS, Diderichsen B. On the Safety of Bacillus Subtilis and B.Amyloliquefaciens - a Review. Appl Microbiol Biot. 1991;36(1):1-4.

11. Stulke J, Hillen W. Regulation of carbon catabolism in Bacillus species. Annual review of microbiology. 2000;54:849-880.

12. Repizo GD, Mortera P, Magni C. Disruption of the alsSD operon of Enterococcus faecalis impairs growth on pyruvate at low pH. Microbiology. 2011;157(9):2708-2719.

13. Nicholson WL. The Bacillus subtilis ydjL (bdhA) gene encodes acetoin reductase/2,3-butanediol dehydrogenase. Appl Environ Microbiol. 2008;74(22):6832-6838.

14. Yang T, Rao Z, Zhang X, Xu M, Xu Z, Yang ST. Improved production of 2,3-butanediol in Bacillus amyloliquefaciens by over-expression of glyceraldehyde-3-phosphate dehydrogenase and 2,3-butanediol dehydrogenase. PLoS One. 2013;8(10):e76149.

15. Yang T, Rao Z, Hu G, Zhang X, Liu M, Dai Y, et al. Metabolic engineering of Bacillus subtilis for redistributing the carbon flux to 2,3-butanediol by manipulating NADH levels. Biotechnol Biofuels. 2015;8:129.

16. Fu J, Wang Z, Chen T, Liu W, Shi T, Wang G, et al. NADH plays the vital role for chiral pure D-(-)-2,3-butanediol production in Bacillus subtilis under limited oxygen conditions. Biotechnol Bioeng. 2014;111(10):2126-2131.

17. Dai JJ, Cheng JS, Liang YQ, Jiang T, Yuan YJ. Regulation of extracellular oxidoreduction potential enhanced (R,R)-2,3butanediol production by Paenibacillus polymyxa CJX518. Bioresour Technol. 2014;167:433-440.

18. Adams MJ, Ellis GH, Gover S, Naylor CE, Phillips C. Crystallographic study of coenzyme, coenzyme analogue and substrate binding in 6-phosphogluconate dehydrogenase: implications for NADP specificity and the enzyme mechanism. Structure (London, England : 1993). 1994;2(7):651-668.

19. Bao T, Zhang X, Zhao X, Rao Z, Yang T, Yang S. Regulation of the NADH pool and NADH/NADPH ratio redistributes acetoin and 2,3-butanediol proportion in Bacillus subtilis. Biotechnol J. 2015;10(8):1298-1306.

20. Fujita Y, Ramaley R, Freese E. Location and properties of glucose dehydrogenase in sporulating cells and spores of Bacillus subtilis. J Bacteriol. 1977;132(1):282-293. 
21. Zhang L, Singh R, D S, Guo Z, Li J, Chen F, et al. An artificial synthetic pathway for acetoin, 2,3-butanediol, and 2-butanol production from ethanol using cell free multi-enzyme catalysis. Green Chem. 2018;20(1):230-242.

22. Hilt W, Pfleiderer G, Fortnagel P. Glucose dehydrogenase from Bacillus subtilis expressed in Escherichia coli. I: Purification, characterization and comparison with glucose dehydrogenase from Bacillus megaterium. Biochim Biophys Acta. 1991;1076(2):298-304.

23. Zhang X, Zhang R, Bao T, Yang T, Xu M, Li H, et al. Moderate expression of the transcriptional regulator ALsR enhances acetoin production by Bacillus subtilis. J Ind Microbiol Biotechnol. 2013;40(9):1067-1076.

24. Yansura DG, Henner DJ. Use of the Escherichia coli lac repressor and operator to control gene expression in Bacillus subtilis. PNAS. 1984;81(2):439-443.

25. Xu S, Wang X, Du G, Zhou J, Chen J. Enhanced production of L-sorbose from D-sorbitol by improving the mRNA abundance of sorbitol dehydrogenase in Gluconobacter oxydans WSH-003. Microb Cell Fact. 2014;13:146.

26. Wu X, Brewer G. The regulation of mRNA stability in mammalian cells: 2.0. Gene. 2012;500(1):10-21.

27. Yang T, Irene K, Liu H, Liu S, Zhang X, Xu M, et al. Enhanced extracellular gamma glutamyl transpeptidase production by overexpressing of PrsA lipoproteins and improving its mRNA stability in Bacillus subtilis and application in biosynthesis of L-theanine. J Biotechnol. 2019;302:85-91.

28. Fradrich C, March A, Fiege K, Hartmann A, Jahn D, Hartig E. The transcription factor AlsR binds and regulates the promoter of the alsSD operon responsible for acetoin formation in Bacillus subtilis. J Bacteriol. 2012;194(5):1100-1112.

29. Biswas R, Yamaoka M, Nakayama H, Kondo T, Yoshida K, Bisaria VS, et al. Enhanced production of 2,3-butanediol by engineered Bacillus subtilis. Appl Microbiol Biotechnol. 2012;94(3):651-658.

30. Guan C, Cui W, Cheng J, Zhou L, Guo J, Hu X, et al. Construction and development of an auto-regulatory gene expression system in Bacillus subtilis. Microb Cell Fact. 2015;14:150.

31. Kopke M, Gerth ML, Maddock DJ, Mueller AP, Liew F, Simpson SD, et al. Reconstruction of an acetogenic 2,3-butanediol pathway involving a novel NADPH-dependent primary-secondary alcohol dehydrogenase. Appl Environ Microbiol. 2014;80(11):3394-3403.

32. Fu J, Huo G, Feng L, Mao Y, Wang Z, Ma H, et al. Metabolic engineering of Bacillus subtilis for chiral pure meso-2,3butanediol production. Biotechnol Biofuels. 2016;9:90.

33. Gao S, Guo W, Shi L, Yu Y, Zhang C, Yang H. Characterization of acetoin production in a budC gene disrupted mutant of Serratia marcescens G12. J Ind Microbiol Biotechnol. 2014;41(8):1267-1274.

34. Ji XJ, Huang H, Zhu JG, Ren LJ, Nie ZK, Du J, et al. Engineering Klebsiella oxytoca for efficient 2, 3-butanediol production through insertional inactivation of acetaldehyde dehydrogenase gene. Appl Microbiol Biotechnol. 2010;85(6):1751-1758.

35. Jung MY, Ng CY, Song H, Lee J, Oh MK. Deletion of lactate dehydrogenase in Enterobacter aerogenes to enhance 2,3butanediol production. Appl Microbiol Biotechnol. 2012;95(2):461-469.

36. Wang Q, Chen T, Zhao X, Chamu J. Metabolic engineering of thermophilic Bacillus licheniformis for chiral pure D-2,3butanediol production. Biotechnol Bioeng. 2012;109(7):1610-1621.

37. Horton RM, Cai ZL, Ho SN, Pease LR. Gene splicing by overlap extension: tailor-made genes using the polymerase chain reaction. BioTechniques. 1990;8(5):528-535.

38. Vojcic L, Despotovic D, Martinez R, Maurer K-H, Schwaneberg U. An efficient transformation method for Bacillus subtilis DB104. Appl Microbiol Biot. 2012;94(2):487-493.

39. Atsumi S, Li Z, Liao JC. Acetolactate synthase from Bacillus subtilis serves as a 2-ketoisovalerate decarboxylase for isobutanol biosynthesis in Escherichia coli. Appl Environ Microbiol. 2009;75(19):6306.

40. Holtzclaw WD, Chapman LF. Degradative acetolactate synthase of Bacillus subtilis: purification and properties. J Bacteriol. 1975;121(3):917-922.

\section{Tables}


Table 1 Strains used in this study

\begin{tabular}{|c|c|c|}
\hline Strains & Relevant characteristic or sequence & Source \\
\hline BMO & B.subtilis168 & Lab stock \\
\hline DH5a & E. coli & Lab stock \\
\hline BM1 & B. subtilis $168 \mathrm{pMA} 5-\mathrm{P}_{\mathrm{bdhA}}-g d h$ & This study \\
\hline BM2 & B. subtilis 168pMA5-P $\mathrm{pac}^{-}$gdh & This study \\
\hline BM3 & B. subtilis $168 \mathrm{pMA} 5 \mathrm{P}_{\mathrm{spac}}-g d h$ & This study \\
\hline BM4 & B. subtilis 168pMA5-P $\mathrm{Hpall}^{-}$gdh & This study \\
\hline BM5 & B. subtilis $168 \mathrm{pMA5}-\mathrm{TDH}$ & This study \\
\hline BM6 & B. subtilis 168pMA5-P $\mathrm{Hpall}^{-T D H R 1}$ & This study \\
\hline BM7 & B. subtilis 168 pMA5- $\mathrm{P}_{\text {Hpall }}-T D H R 2$ & This study \\
\hline BM8 & B. subtilis 168 pMA5- $\mathrm{P}_{\text {Hpall }}-T D H R 3$ & This study \\
\hline BM9 & B. subtilis 168 pMA5- $\mathrm{P}_{\text {Hpall }}-T D H R 4$ & This study \\
\hline BM10 & B. subtilis $168 \mathrm{pMA5}-\mathrm{P}_{\mathrm{Hpall}}-\mathrm{TDHR5}$ & This study \\
\hline BM11 & B. subtilis 168 pMA5- $\mathrm{P}_{\text {Hpall }}-T D H R 5-\mathrm{P}_{\mathrm{bdh}}-g d h$ & This study \\
\hline BM12 & B. subtilis 168 pMA5- $\mathrm{P}_{\mathrm{Hpall}}-T D H R 5-\mathrm{P}_{\mathrm{pac}}-g d h$ & This study \\
\hline BM13 & B. subtilis $168 \mathrm{pMA} 5-\mathrm{P}_{\mathrm{Hpall}}-T D H R 5-\mathrm{P}_{\mathrm{spac}}-g d h$ & This study \\
\hline BM14 & B. subtilis 168 pMA5- $\mathrm{P}_{\text {Hpall }}-T D H R 5-\mathrm{P}_{\text {Hpall }}-g d h$ & This study \\
\hline BM15 & B. subtilis $168 \Delta / d h A \mathrm{P}_{\text {srfA }}$-alsr. pMA5-P $\mathrm{Hpall}-T D H R 5-\mathrm{P}_{\mathrm{pac}}-g d h$ & This study \\
\hline
\end{tabular}

Table 2 plasmids and primers used in this study 


\begin{tabular}{|c|c|c|}
\hline Plasmid or Primer & Relevant characteristic & Source \\
\hline \multicolumn{3}{|l|}{ Plasmid } \\
\hline p7Z6 & $z^{2}{ }^{r}$, Amp ${ }^{r}$ containing zeo and cre, lox gene & Lab stock \\
\hline pDG148 & $\operatorname{Kan}^{r}$ & Lab stock \\
\hline pMA5 & E. coli-B. subtilis shuttle vector (in E. coli, Ap ${ }^{r}$; in B. subtilis, $\operatorname{Kan}^{r}$ ) & Lab stock \\
\hline pMA5- $\mathrm{P}_{\mathrm{bdhA}}-g d h$ & $g d h$ under $\mathrm{P}_{\mathrm{bdhA}}$ promote & This study \\
\hline pMA5-P $\mathrm{pac}-g d h$ & gdh under $\mathrm{P}_{\mathrm{pac}}$ promote & This study \\
\hline pMA5 $P_{\text {spac }}-g d h$ & $g d h$ under $\mathrm{P}_{\text {spac }}$ promote & This study \\
\hline pMA5-P ${ }_{\text {Hpall- }}-g d h$ & gdh under $\mathrm{P}_{\text {Hpall }}$ promote & This study \\
\hline pMA5- $\mathrm{PHpall}-T D H$ & $T D H$ under $\mathrm{P}_{\text {Hpall }}$ promoter & This study \\
\hline pMA5-P Hpall $^{-T D H R 1}$ & TDHR1 under $\mathrm{P}_{\text {Hpall }}$ promoter & This study \\
\hline pMA5- $\mathrm{P}_{\text {Hpall }}-T D H R 2$ & TDHR2 under $\mathrm{P}_{\text {Hpall }}$ promoter & This study \\
\hline pMA5-P ${ }_{\text {Hpall }}-T D H R 3$ & TDHR3 under $\mathrm{P}_{\mathrm{Hpall}}$ promoter & This study \\
\hline pMA5-P $\mathrm{Hpall}_{\text {HI }}$ TDH & TDHR4 under $\mathrm{P}_{\text {Hpall }}$ promoter & This study \\
\hline pMA5-P $\mathrm{Hpall}^{-T D H R 5}$ & TDHR5 under $\mathrm{P}_{\text {Hpall }}$ promoter & This study \\
\hline pMA5- $\mathrm{P}_{\text {Hpall }}-T D H R 5-\mathrm{P}_{\mathrm{bdh}}-g d h$ & TDHR5 and $g d h$ under $\mathrm{P}_{\mathrm{bdhA}}$ promoter & This study \\
\hline pMA5- $\mathrm{P}_{\text {Hpall }}-T D H R 5 \mathrm{P}_{\mathrm{pac}}-g d h$ & TDHR5 and $g d h$ under $\mathrm{P}_{\mathrm{pac}}$ promoter & This study \\
\hline pMA5-P $\mathrm{Hpall}^{-T D H R 5} \mathrm{P}_{\mathrm{Hpall}}-g d h$ & TDHR5 and $g d h$ under $\mathrm{P}_{\text {Hpall }}$ promoter & This study \\
\hline pMA5-P ${ }_{\text {Hpall }}-T D H R 5 P_{\text {Spac }}-g d h$ & TDHR5 and $g d h$ under $\mathrm{P}_{\mathrm{spac}}$ promoter & This study \\
\hline \multicolumn{3}{|l|}{ Primer } \\
\hline $\mathrm{P} 1$ & \multicolumn{2}{|l|}{ GCATCGCGCGCGGGGAATTCCGCACAATCCCAATGTCCAAGT } \\
\hline P2 & \multicolumn{2}{|l|}{ CGACTTTTCCTTTTAAATCCGGATACATGGATTACCACTCCTATAACTTTTGATGT } \\
\hline P3 & \multicolumn{2}{|l|}{ GCATCGCGCGCGGGGAATTCGGTGGAAACGAGGTCATCATTTCC } \\
\hline P4 & \multicolumn{2}{|l|}{ CTTTTAAATCCGGATACATCAAAATCGTCTCCCTCCGT } \\
\hline P5 & \multicolumn{2}{|l|}{ GCATCGCGCGCGGGGAATTCGAATTCTACACAGCCCAGTCCAG } \\
\hline P6 & \multicolumn{2}{|l|}{ CTTTTAAATCCGGATACATGAATTCTAGATACACCTCCTTAAGCTT } \\
\hline P7 & \multicolumn{2}{|l|}{ GGCATCGCGCGCGGGGAATTCCTGAGTCTGGCTTTCGGTAAGC } \\
\hline P8 & \multicolumn{2}{|l|}{ TTTTCCTTTTAAATCCGGATACATTAAATCGCTCCTTTTTAGGTGGCAC } \\
\hline P9 & \multicolumn{2}{|l|}{ ATGTATCCGGATTTAAAAGGAAAAGTCG } \\
\hline P10 & \multicolumn{2}{|l|}{ TCGAGCTCTCCCGGGAATTCTTAACCGCGGCCTGCC } \\
\hline P11 & \multicolumn{2}{|l|}{ GCTCGACTCTAGAGGATCCTTAAAGAAGAGACTTGTCTGG } \\
\hline P12 & \multicolumn{2}{|l|}{ AAAGGAGCGATTTACATATGATGAAGGCCGTTCTTTGGTA } \\
\hline
\end{tabular}

Page $11 / 15$ 


\begin{tabular}{|c|c|}
\hline P13 & GCTCGACTCTAGAGGATCCTTAAAATTTAAGAAGAGACTTGTCTGGCGT \\
\hline P14 & GCTCGACTCTAGAGGATCCTTATTTAAATTTAAGAAGAGACTTGTCTGGCGT \\
\hline P15 & GCTCGACTCTAGAGGATCCTTAAAATTTAAATTTAAGAAGAGACTTGTCTGGCGT \\
\hline P16 & GCTCGACTCTAGAGGATCCTTATTTTTTAAATTTAAGAAGAGACTTGTCTGGCGT \\
\hline P17 & GCTCGACTCTAGAGGATCCTTATTTTTTAAGAAGAGACTTGTCTGGCGT \\
\hline P18 & ACCATGATTACGAATTCGAGCTC \\
\hline P19 & ACGTTGTAAAACGACGGCC \\
\hline P20 & TGGCTGGACAGCCTGAGG \\
\hline P21 & GAGCTCGAATTCGTAATCATGGTTAATCATCCTTCCAGGGTATGTTTCTC \\
\hline P22 & GGCCGTCGTTTTACAACGTCCGCAACTTTAGAGTAAAGGGCT \\
\hline P23 & CAGCCCGCCTTCTTGGAA \\
\hline P24 & GGTACCTCTAGAAGAAGCTTATCGACAAAAATGTCATGAAAGAATCGT \\
\hline P25 & AGATGGCGAAGCTCCATATTGTCATACCTCCСCTAATCTTTATAAGC \\
\hline P26 & ATGGAGCTTCGCCATCTTCAA \\
\hline P27 & TCGAGCTCTCCCGGGAATTCTCATGTACCTGCATCACTCTC \\
\hline P28 & CTGGGAGAAAAATGCCGAGAT \\
\hline P29 & GGAAACTCGTGGCGATAAGC \\
\hline P30 & TCCACGCCGTAAACGATGA \\
\hline P31 & TTCCTTTGAGTTTCAGTCTTGCG \\
\hline
\end{tabular}

Table 3 Metabolic characterizations of B. subtilis strains cultivated in fermentation medium supplemented with $100 \mathrm{~g} / \mathrm{L}$ glucose 


\begin{tabular}{|c|c|c|c|c|c|c|c|c|}
\hline Strains & Time(h) & $O D_{600}$ & $\begin{array}{l}\text { 2,3-BDO } \\
\text { (g/L) }\end{array}$ & $\begin{array}{l}A C \\
(g / L)\end{array}$ & $\begin{array}{l}\text { Lactate } \\
(\mathrm{g} / \mathrm{L})\end{array}$ & $\begin{array}{l}\text { Ethanol } \\
(\mathrm{g} / \mathrm{L})\end{array}$ & $\begin{array}{l}\text { Intracellular } \\
\text { NADH } \\
(\mu \mathrm{mol} / \mathrm{L} / \mathrm{OD} \\
600)\end{array}$ & $\begin{array}{l}\text { Intracellular } \\
\text { NADPH } \\
(\mu \mathrm{mol} / \mathrm{L} / \mathrm{OD} \\
600)\end{array}$ \\
\hline BMO & $72 \pm 2$ & $15.20 \pm 0.13$ & $34.60 \pm 0.29$ & $14.75 \pm 0.15$ & $5.46 \pm 0.19$ & $0.93 \pm 0.05$ & $1.90 \pm 0.13$ & $1.49 \pm 0.15$ \\
\hline BM1 & $78 \pm 1.5$ & $14.32 \pm 0.34$ & $29.36 \pm 0.39$ & $17.35 \pm 0.37$ & $4.63 \pm 0.31$ & $0.63 \pm 0.12$ & $1.80 \pm 0.11$ & $1.69 \pm 0.13$ \\
\hline BM2 & $80 \pm 3$ & $14.25 \pm 0.56$ & $28.25 \pm 0.50$ & $18.06 \pm 0.45$ & $4.49 \pm 0.39$ & $0.61 \pm 0.13$ & $1.74 \pm 0.09$ & $1.72 \pm 0.17$ \\
\hline BM3 & $84 \pm 2$ & $14.23 \pm 0.23$ & $27.83 \pm 0.83$ & $19.54 \pm 0.54$ & $4.35 \pm 0.36$ & $0.59 \pm 0.23$ & $1.69 \pm 0.07$ & $1.78 \pm 0.14$ \\
\hline BM4 & $84 \pm 1.5$ & $14.03 \pm 0.19$ & $26.90 \pm 0.75$ & $20.31 \pm 0.38$ & $4.20 \pm 0.26$ & $0.58 \pm 0.28$ & $1.62 \pm 0.01$ & $1.83 \pm 0.11$ \\
\hline BM11 & $72 \pm 2$ & $14.15 \pm 0.25$ & $38.13 \pm 0.19$ & $12.03 \pm 0.24$ & $4.83 \pm 0.30$ & $0.86 \pm 0.03$ & $1.86 \pm 0.02$ & $1.51 \pm 0.09$ \\
\hline BM12 & $72 \pm 2$ & $14.38 \pm 0.16$ & $39.45 \pm 0.23$ & $11.41 \pm 0.16$ & $4.76 \pm 0.35$ & $0.71 \pm 0.07$ & $1.83 \pm 0.05$ & $1.54 \pm 0.12$ \\
\hline BM13 & $73 \pm 1.5$ & $14.25 \pm 0.45$ & $37.45 \pm 0.25$ & $12.35 \pm 0.26$ & $4.68 \pm 0.19$ & $0.69 \pm 0.09$ & $1.79 \pm 0.07$ & $1.58 \pm 0.16$ \\
\hline BM14 & $73 \pm 1.5$ & $14.24 \pm 0.36$ & $36.03 \pm 0.13$ & $12.45 \pm 0.17$ & $4.58 \pm 0.24$ & $0.60 \pm 0.08$ & $1.75 \pm 0.05$ & $1.64 \pm 0.10$ \\
\hline
\end{tabular}

The intracellular NADH and NADPH of BM1هBM2هBM3囚BM4 were extracted at $72 \mathrm{~h} \otimes T$ The intracellular NADH and NADPH of other strains were extracted at $60 \mathrm{~h}$.

\section{Figures}

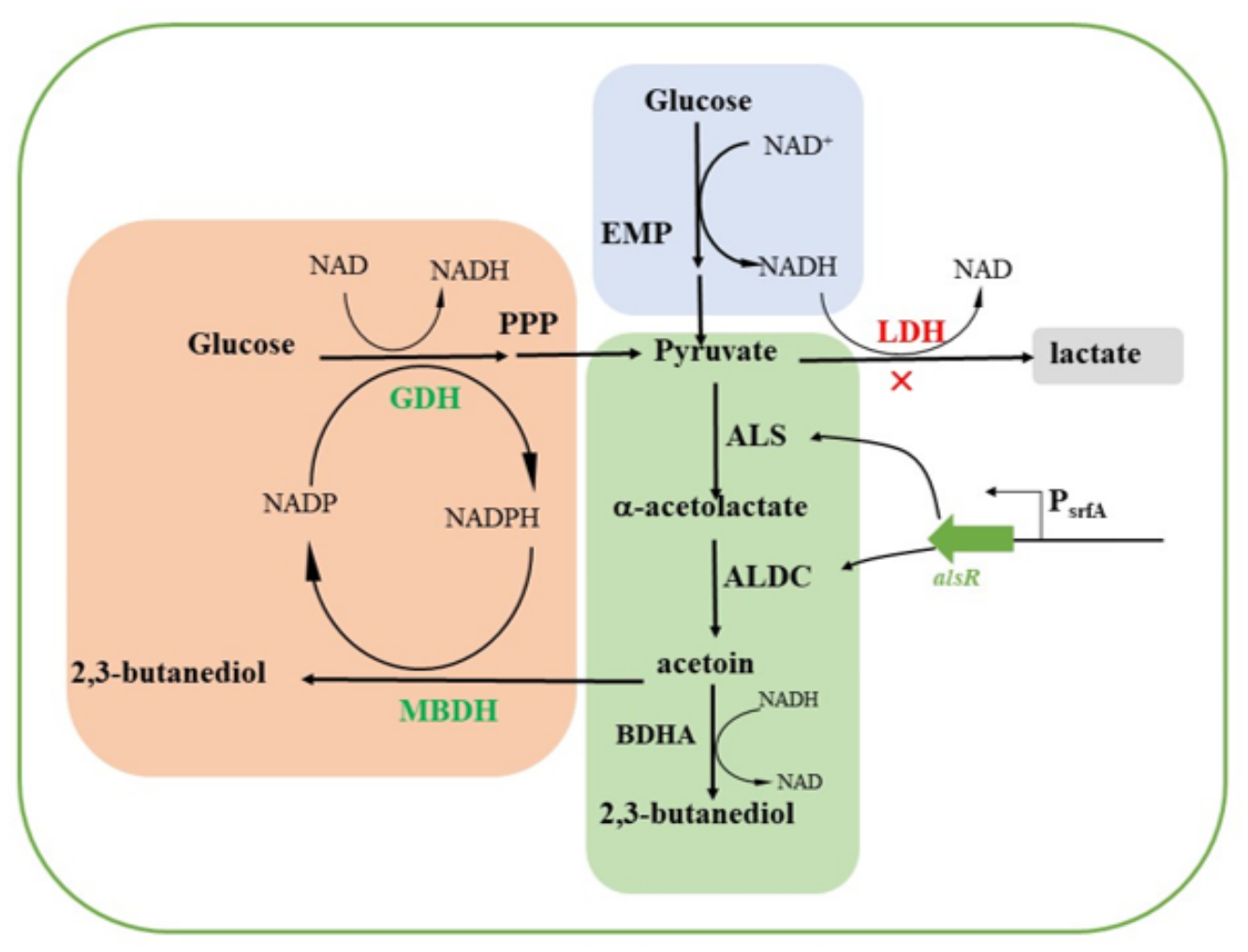

Figure 1

The 2,3-BDO biosynthetic pathway in $\mathrm{B}$. subtilis GDH, glucose dehydrogenase; ALS, acetolactate synthase; ALDC, acetolactate decarboxylase; LDH, lactate dehydrogenase; AlsR, transcriptional regulator; TDH, NADPH-dependent 2, 3- 
butanediol dehydrogenase.

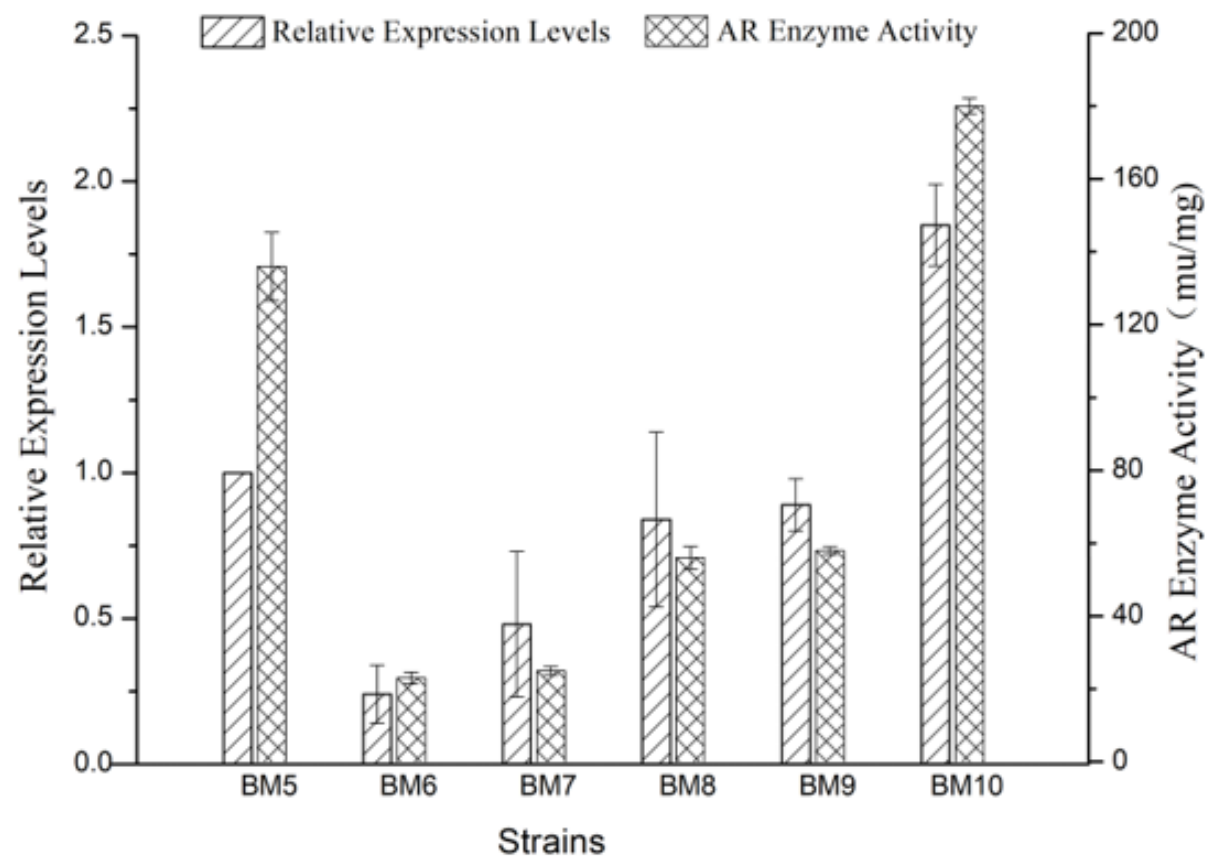

\section{Figure 2}

Transcriptional levels and activity of TDH in the recombinant strains. BM5, the control strain; BM6, strain with TDHR1; BM7, strain with TDHR2; BM8, strain with TDHR3; BM9, strain with TDHR4; BM10, strain with TDHR5; the 16S rRNA gene was used as the internal control gene to normalize the results. Error bars: Standard deviation (SD) $(n=3)$. 

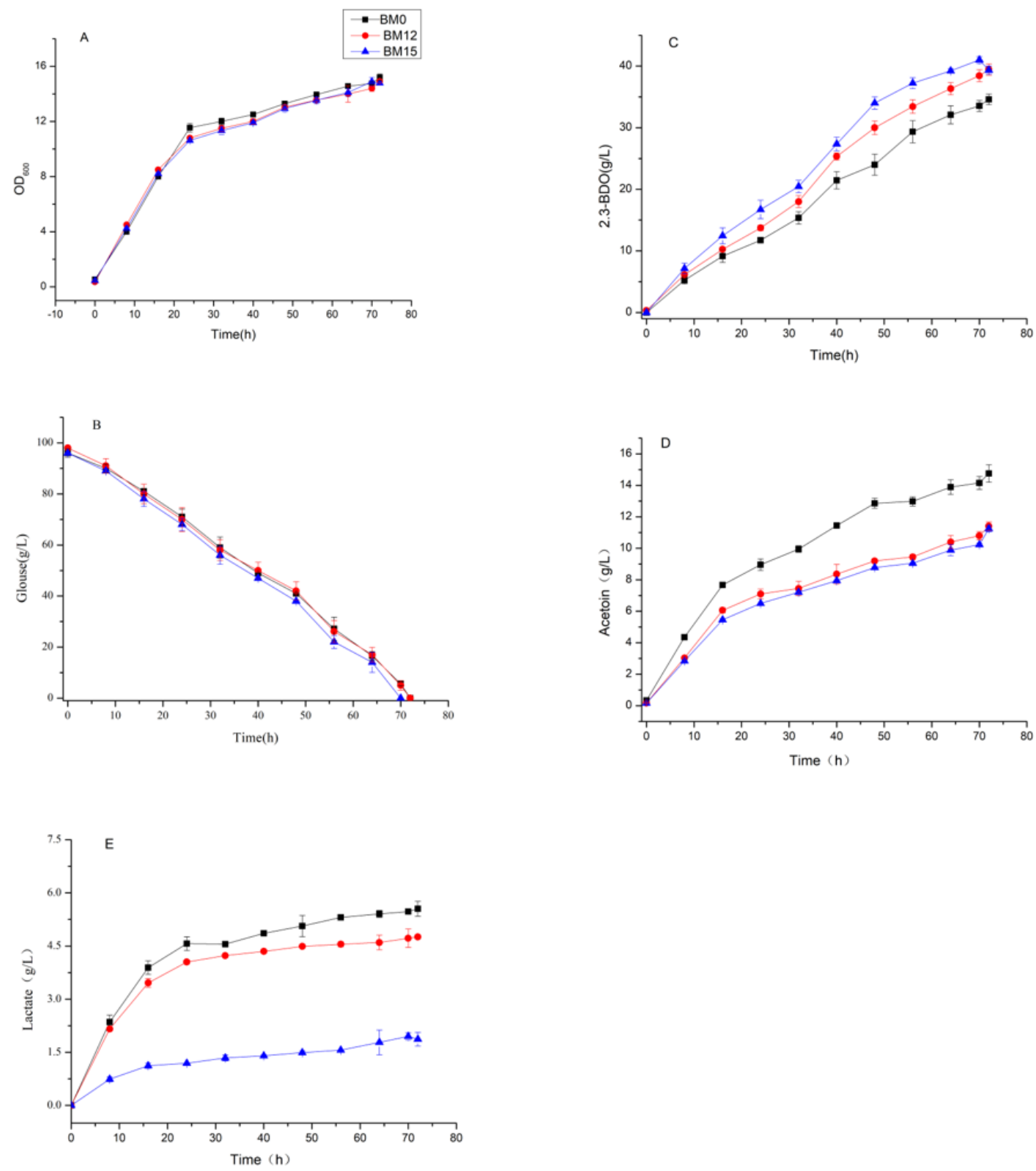

\section{Figure 3}

Time profiles of 2,3-BD fermentation with various strains (A cell growth; B glucose consumption; C 2,3-BD production; D acetoin formation; E lactate production). Fermentation was carried out at $37^{\circ} \mathrm{C}$ in $50 \mathrm{~mL}$ fermentation medium. BM0 strain, B. subtilis 168 BM12 strain, B. subtilis 168 with plasmid pMA5-PHpall-TDHR5-Ppac-gdh; BM15 strain, B. subtilis 168 $\Delta$ ldhA PsrfA-alsr: plasmid pMA5-PHpall-TDHR5-Ppac-gdh;) Error bars: Standard deviation (SD) $(n=3)$. 